\title{
ALTERAÇÕES GASTROINTESTINAIS EM NONAGENÁRIOS E CENTENÁRIOS DURANTE O ISOLAMENTO SOCIAL
}

Cintia Cristina Sulzbach; Escola de Medicina da PUCRS, Projeto de extensão Atenção Multiprofissional ao Longevo (AMPAL), Porto Alegre, Brasil; cintia.sulz@gmail.com

Renata Breda Martins; Escola de Medicina da PUCRS, Projeto de extensão Atenção Multiprofissional ao Longevo (AMPAL), Porto Alegre, Brasil; nutrirenatamartins@gmail.com

Antonia Angeli Gazola; Escola de Medicina da PUCRS, Projeto de extensão Atenção Multiprofissional ao Longevo (AMPAL), Porto Alegre, Brasil; antonia.gazola@acad.pucrs.br

Angelo José Gonçalves Bós; Escola de Medicina da PUCRS, Projeto de extensão Atenção Multiprofissional ao Longevo (AMPAL), Porto Alegre, Brasil; angelo.bos@pucrs.br

\section{RESUMO}

Introdução: A pandemia por COVID-19 demandou uma restrição social principalmente à população de risco como os longevos ( $\geq 90$ anos), o que é um fator de risco para o desenvolvimento de alterações gastrointestinais, comuns em nonagenários e centenários. Objetivos: Descrever a prevalência de alterações gastrointestinais em nonagenários e centenários durante a pandemia por COVID-19. Métodos: Estudo transversal e observacional envolvendo participantes do projeto Atenção Multiprofissional ao Longevo, avaliados por telefone no período de março a agosto de 2020. As variáveis investigadas foram características sociodemográficas e de hábitos alimentares e mudança de sintomas gastrointestinais durante a pandemia. Foram calculadas frequências e média para descrição. Resultados: Participaram da pesquisa 59 nonagenários e centenários, a maioria mulheres (77\%) com média de 96,0 $\pm 3,8$ anos, brancos (76\%), viúvas (73\%), residindo com acompanhante (81\%). Quanto à saúde em geral, 51\% considerou ótima/boa $(n=30)$. Em 59\% $(n=35)$ referiram ter algum sintoma no trato digestório antes da pandemia. A maior parte $(93 \%, \mathrm{n}=55)$ afirmou não ter mudanças no trato digestório durante a pandemia. Em relação à consistência das fezes, $44 \%$ referiu fezes normais $(n=26)$. Um quarto dos participantes relatou constipação $(n=15)$. A constipação foi mais frequente entre os participantes que consumiam < 1litro/dia (44\%) dos que consumiam mais (35\%, $\mathrm{p}=0.3722)$. Conclusão: Os longevos avaliados não tiveram mudanças frequentes nos sintomas gastrointestinais durante a pandemia do COVID-19. Constipação foi o sintoma mais comum, relacionada com o consumo de água. Menor mobilidade também está relacionada ao aumento da constipação.

Palavras-chave: Saúde do Idoso; Gastroenteropatias; COVID-19 